\title{
Phenomenal evidence and factive evidence defended: replies to McGrath, Pautz, and Neta
}

\author{
Susanna Schellenberg ${ }^{1}$
}

Published online: 22 August 2015

(C) Springer Science+Business Media Dordrecht 2015

\begin{abstract}
This paper defends and develops the capacity view against insightful critiques from Matt McGrath, Adam Pautz, and Ram Neta. In response to Matt McGrath, I show why capacities are essential and cannot simply be replaced with representational content. I argue moreover, that the asymmetry between the employment of perceptual capacities in the good and the bad case is sufficient to account for the epistemic force of perceptual states yielded by the employment of such capacities. In response to Adam Pautz, I show why a perceiver's belief is better justified than the belief of someone who suffers a subjectively indistinguishable hallucination. I show, moreover, why the capacity view is compatible with standard Bayesian principles and how it accounts for degrees of justification. In response to Ram Neta, I discuss the relationship between evidence and rational confidence, as well as the notion of evidence in light of an externalism about perceptual content.
\end{abstract}

Keywords Phenomenal evidence - Factive evidence - Perceptual capacities · Degrees of justification - Rational confidence $\cdot$ Bayesianism

\section{Introduction}

In "Phenomenal Evidence and Factive Evidence" I argue that perceptual experience provides us with phenomenal evidence and in the good case with additional factive evidence. Matt McGrath, Adam Pautz, and Ram Neta have each responded with insightful critiques of my argument. I am grateful to them for continuing the discussion in such a thoughtful way. In what follows, I will briefly state my view, and will then respond to each of their comments in turn.

Susanna Schellenberg

susanna.schellenberg@rutgers.edu

1 Rutgers, New Brunswick, NJ, USA 
I argue that it is because an experiencing subject is employing perceptual capacities with a certain nature that her perceptual states have epistemic force. The notion of a capacity is understood to be explanatorily basic. Among capacity views there is a distinction to be drawn between normative capacity views, on which mental capacities are understood as virtues or in other normative ways, and capacity views that forego normative terms. ${ }^{1}$ I aim to defend a version of the capacity view that is distinctly non-normative and non-reliabilist. On the proposed view, employing perceptual capacities yields a mental state with a certain representational content. A perceptual experience can be individuated with regard to the content type that is determined by the capacities employed in perceptual experience. Alternatively, each perceptual experience can be individuated with regard to the environment-dependent token content that ensues from employing perceptual capacities in a particular environment. Insofar as the perceptual capacities employed are the very same in subjectively indistinguishable experiences, the content type will be the same. So there is a metaphysically substantive common element between the good and the bad case. So the capacity view is non-disjunctivist, yet externalist.

Individuating experiences by a content type amounts to individuating experiences with regard to the experiencing subject's sensory state. Phenomenal evidence is determined by the content type of a perceptual experience. Factive evidence is determined by the environment-dependent token content of a perceptual experience. So the factive evidential basis changes as the token content changes-even if one cannot tell. In this sense, factive evidence provides the perceiver with evidence that goes beyond mere phenomenal evidence. So the distinction between phenomenal and factive evidence emerges from two levels of perceptual content.

When I speak of mental states as yielded by employing perceptual capacities, I mean to be saying that the person can-as currently constituted, and not merely via some sort of intensive training regimen-successfully make certain characteristicof-that-mental-state discriminations in certain sorts of cases (good cases). For instance, take the fact that Sara is in the mental state of perceiving red. I am identifying this fact with Sara's ability (as she is currently constituted) to successfully discriminate red from green and other colors. So capacity talk boils down to how the person as currently constituted would fare in the good case. When I say that I understand mental states in terms of capacities, I mean the general thesis that all facts about a subject being in a given mental state should be understood in terms of the person having the capacity to make characteristic-of-that-mental-state discriminations in the good case. For current purposes, a more restricted thesis will do: when considering epistemically relevant mental states in the context of epistemic evaluation, such mental states are to be understood in such contexts in terms of capacities to succeed in the good case.

\footnotetext{
1 For the former, see Sosa (1991), Greco (2001) and Bergmann (2006). For capacity views that forgo normative terms, see Burge (2003), Graham (2011) and Schellenberg (2013a, 2014a).
} 


\section{Reply to McGrath}

I am grateful to McGrath for his thoughtful, challenging, and detailed comments. McGrath elegantly articulates a competitor view supported by three powerful arguments. He suggests moving from the capacity-first account of perceptual evidence (as I provide) to a mental-state-first account (as he prefers). He raises three converging objections to my view: (1) content properties are fundamentally epistemically relevant and capacities are not, (2) my account does not generate the intuitive verdicts about the bad case (though I claim otherwise), and (3) my account does not handle singular but nondemonstrative perceptual beliefs. I will consider these in turn.

\subsection{Contents versus capacities}

By sketching a view that is very much like mine in terms of working with content tokens and content types, and having two notions of evidence-factive evidence and phenomenal evidence-keyed to these contents, McGrath sharply puts into focus the key elements of the capacity view. The only difference between the capacity view and the alternative view that McGrath sketches is that, while the former explains the epistemic force of perceptual content in terms of the perceptual capacities that yield these contents, the latter does not. The alternative view simply imbues these contents with epistemic force directly. This enables McGrath to crisply pose the question of why we need to take the extra step of moving from contents to capacities.

In response, I offer two connected reasons why we cannot stop at the level of the contents themselves and need to bring in perceptual capacities. First, content itself-without mention of what sort of propositional attitude is involved-cannot provide epistemic force in itself. The fact that I am in some way bearing some attitude to the content that the cat is on the mat leaves open whether my attitude is one of belief, doubt, hope, or fear. No one thinks that hopes or fears have epistemic force.

Now in fairness, McGrath does not simply appeal to content but includes that it is an experience. For instance, he says:

Why does your experience as of a white cup justify you in believing of the cup that it is white? The first-stab answer is: because it is an experience having the singular content concerning that cup that it is white. The question is why this first stab wouldn't be the end of the epistemic story, as far as facts about the experience are concerned (McGrath 2015).

So really, McGrath's alternative view does not stop at the level of content, but rather at the level of experiences with content. And this is apt: McGrath thereby blocks hopes and fears from having epistemic force, despite the fact that they have content too.

But secondly, McGrath does nothing to explain why experiences-with-content have any more epistemic force than hopes-with-content or fears-with-content. $\mathrm{He}$ 
does not address the question of what is so epistemically forceful about experience. As I see it, this is the core question. And so McGrath's first stab answer cannot be the end of the epistemic story, insofar as the epistemic story should (inter alia) offer a satisfying answer to what is epistemically special about experience.

Here is where capacities come in. I argue that experiences have epistemic force in virtue of the perceptual capacities employed that function to single out particulars in the environment. It is because the capacities involve function differently in experience than they do in hoping and in fearing, that experiences-with-content can have more epistemic force than hopes-with-content or fears-with-content. Perception is our primordial connection to particulars in our environment. The crucial difference between perception, on the one hand, and beliefs, hopes, fears, and imaginations on the other, is that perceptual capacities function to single out the particulars to which we are perceptually related, while the capacities employed in those other mental states do not necessarily have this function. This is why we need to take the extra step of moving from contents to capacities.

I suppose McGrath could say that it is just a basic fact about evidence that experience has a distinctive connection to evidence. His analogy with the role of suffering in value theory seems to suggest this line: Just as suffering might be a primitive notion from the perspective of value theory, so experience might be a primitive notion from the perspective of epistemology. Of course it is hard to argue against a primitivist view, save to say that primitivism should generally be a theoretical last resort, to be accepted only when all satisfying explanations fail. I have tried to provide a satisfying explanation in terms of capacities.

In short, both the notion of content and the notion of experience that McGrath appeals to need explaining. Neither notion is well suited to be explanatory basic. I explain the notion of content as well as the notion of sensory perceptual states in a unified way in terms of employing perceptual capacities, arguing that there is an explanatory and metaphysical primacy of the good case over the bad case given that capacities function to do what they do in the good case.

Now McGrath thinks I need more than this and offers two ways I might supplement the capacity view: (1) by appealing to a reliabilist account of capacities or (2) by appealing to the reliability of conditions explanatory of one's having the capacity. As McGrath notes, I do not in any way appeal to a reliabilist account, be it of the first or the second, broadly Burgean, variety. I do not need to. Here is an attempt to explain why. I argue that sensory states are systematically linked to particulars of the type that the sensory state is of in the good case in the sense that the perceptual capacities employed in the bad case are explanatorily and metaphysically parasitic on their employment in the good case. There is an explanatory primacy of the good over the bad case since one can give an analysis of the perceptual capacities employed in the bad case only by appealing to their role in the good case. This explanatory primacy is licenced by a metaphysical primacy of the good over the bad case: There is such a metaphysical primacy insofar as perceptual capacities are determined by relations between perceivers and their environment insofar as the function of the capacity is to differentiate and single out, say, instances of red in perception. 
On one way of understanding metaphysical primacy, we can associate things with natures and see if the nature of one thing makes reference to another. If so, the latter will be said to be primary and the former secondary. We can then construct chains so that if the nature of $A$ makes reference to $B$, and the nature of $B$ makes reference to $C$, then $C$ will be primary, $B$ secondary, and $A$ tertiary. According to the capacity view, the bad case is by nature a case brought about by the subject employing her perceptual capacities, and these capacities are by nature defined in terms of success in the good case. So on this pattern, we get the good case coming out primary and the bad case coming our secondary. This is not the only way to use talk of metaphysical primacy but it is one plausible way of using the term.

In speaking of it being the function of perceptual capacities to single out the relevant particulars, I do not mean to speak of their reliability but rather of how they are to be understood metaphysically. It is the function of a perceptual capacity to single out, say, instances of red. This is so regardless of how often the capacity is employed successfully to single out an instance of red. More generally, if a subject's environment sensorily seems to contain $F$ particulars, then she is in a sensory state that is determined by employing perceptual capacities that function to single out $F$ particulars. Now, given that perceptual capacities can be employed while failing to single out $F$ particulars, one might ask why they function to single out particulars rather than fail to do so. What explains the asymmetry? In response, any plausible account of natural function will support the idea that the heart has the function to pump blood rather than the function to fail to pump blood. This is so even though hearts may fail to pump blood. Likewise, perceptual capacities have the function to single out particulars in the environment rather than to fail to do so. This is even though they may fail to single out a particular. An evolutionary account of function would posit that perceptual capacities evolved for the purpose of singling out particulars rather than for the purpose of failing to single out particulars: they were selected to single out particulars. However, there is no need to explain the asymmetry in evolutionary terms or in any other reliabilist terms. On any plausible account of natural function, we can say that perceptual capacities function to single out particulars rather than fail to do so. In this sense, the idea of a natural function is not tied into the idea of these functions being reliable or the conditions explanatory of a system having that capacity being reliable.

If this is right, then the epistemic force of perceptual experience neither relies on perceptual capacities being reliable nor on the reliability of conditions explanatory of one's having the capacity. On the suggested capacity view, if a subject is in a sensory state that is determined by employing perceptual capacities that function to single out $F$ particulars, then she is in a sensory state that provides evidence for the presence of $F$ particulars. It is rational to heed the testimony of our senses since sensory states are systematically linked to the particulars that they are of in the good case. The notion of systematic linkage in play is understood in terms of a metaphysical and explanatory primacy notion rather than a reliabilist notion. Now, the perceptual capacities employed in perception may happen to be reliable. However, even in this case it is the primacy of the good over the bad case that gives experience its epistemic force. 
As McGrath notes, part of what is at issue in whether or not one invokes reliability is what one can say about Swampman cases, in which an atom-by-atom duplicate of a human being forms spontaneously when lightning strikes a swamp. Intuitively one wants to say that Swampman's experience can provide him evidence. I can say this, provided it is agreed that Swampman's perceptual capacities function to single out particulars just as ours do. So, I can give the intuitive response that Swampman has evidence even though he has no past interactions with anything and lacks ancestors.

\subsection{Hallucination and singular beliefs?}

McGrath worries that my "treatment of Percy and Hallie underestimates the epistemological credentials of Hallie's beliefs." Consider Percy who perceives a white cup and Hallie who suffers a subjectively indistinguishable hallucination as of a white cup. Hallie does not know she is hallucinating. As far as she can tell, she is perceiving. On the basis of their experiences, Percy and Hallie both form a belief that can be expressed with the utterance "that is a white cup". I argue that Percy has more evidence than Hallie for his belief: Percy has factive evidence in addition to phenomenal evidence. Hallie has only phenomenal evidence.

McGrath imagines Hallie declaring "that is a white cup" and thereby expressing a justified singular belief. But, McGrath continues, “for Schellenberg Hallie's singular belief isn't justified, because there is no evidence for it, no factive and no phenomenal evidence." McGrath argues that Hallie has no factive evidence since she is hallucinating, and no phenomenal evidence for the singular proposition since phenomenal evidence is only for general propositions.

First, there is a terminological issue of whether we call Hallie's belief a singular belief. McGrath uses "singular belief" in such a way that singular beliefs need not have singular contents. So the way he uses the term, Hallie's claim "that cup is white" expresses a singular belief even though it has a gappy content. By contrast, I am using "singular belief" in such a way that singular beliefs always have singular content. So the way I am using the term, Hallie does not have a singular belief. So while Hallie might say, "that cup is white", the content of that belief is not a singular proposition, even though it has the form of a singular belief. It is not a singular propositions, since "that" has no referent. So the content cannot be a singular proposition since Hallie fails to refer. ${ }^{2}$

In response to McGrath, if "singular belief" means belief with singular content, McGrath is wrong that (on my view) Hallie has a singular belief. If, however, "singular belief" means whatever belief is expressed by the relevant demonstrative utterances, then mcgrath is wrong that (on my view) Hallie's singular belief isn't justified. In short, Hallie's belief "that cup is white” is justified by her phenomenal

\footnotetext{
2 Jeshion (2010), Sainsbury (2010) and Crane (2011) have recently argued in different ways against the view that singular thought is object dependent. They argue that what makes a thought singular is its form rather than its content. When I argue that a gappy content is singular in form though not in content this would qualify as a singular thought on such a view. Thanks to James Genone and David Chalmers for helpful discussions on this issue.
} 
evidence, contrary to what McGrath says. While I argue that Hallie's belief "that cup is white" does not have singular content, it is certainly true that it seems to Hallie that a particular is present. That is precisely what the notion of phenomenological particularity captures. It does not, however, follow from the fact that it seems to her that a particular is present that her general belief depends for its justification on her singular belief that there is a white cup present being justified. To argue that it does would be to conflate how things seem to one (an entirely subjective matter) with what has justificatory force (a matter beyond the subjective). Contra McGrath, I argue that Hallie has some justification for her belief "that cup is white". It seeming to her that there is a cup present provides some justification for her belief "that is a white cup". It provides phenomenal evidence. Hallie does not possess evidence for that part of her belief that purports to pertain to a particular. This is a good outcome since-unbeknownst to Hallie-her belief does not in fact pertain to a particular. It only purports to do so.

Now McGrath argues: "If we rely on the standard proper-basing requirement on doxastic justification, then we must conclude that Hallie's general belief is justified only if and because her singular belief is. If Schellenberg has to declare the singular belief unjustified, she seems forced to declare Hallie's general belief unjustified as well." As I understand this, McGrath is thinking that Hallie forms the general belief "there is a white cup here" on the basis of the singular belief "that is a white cup", so that the general belief must inherit justification from the singular belief. In response, as I argued above, I do not consider Hallie's belief "that cup is white" to be a singular belief, however, I do consider it to be justified in virtue of Hallie having phenomenal evidence. So I do argue that Hallie has a justified general belief that there is a white cup here. I can allow that the gappy token content that characterizes Hallie's hallucinatory state can support the general belief in virtue of its type.

\subsection{Encountering the unknown}

McGrath distills the following principle from my discussion of identical twin cases:

If the object $\alpha$ enters into the token content of one's experience, then one is prima facie justified in believing that $\alpha$ is present (McGrath 2015).

He then worries that this is "overly strong" on the basis of the following case:

Suppose I happen to see a man on the street. He happens to be Bob Edwards, the former NPR host. Am I prima facie justified in believing it is Bob Edwards? No, and not because I have a special defeater. I have no idea what Bob Edwards looks like. Looking at him, there is no prima facie support from my experience for Bob Edward is present that is overridden or defeated (McGrath 2015).

McGrath has my principle right, and I agree with his judgment on the Bob Edwards case. But I disagree that my principle has any consequences for the Bob Edwards case. Being Bob Edwards need not be a perceivable property and so need not enter into the token content of one's experience (which is what my principles concerns). 
So although we see a person who happens to be Bob Edwards the fact that it is Bob Edwards need not enter into the content of the experience. I am not saying that such facts never enter the content of experience. I am saying only that they need not. That said, I am inclined to think that such facts never enter the content of experience. But for present purposes I need only the weaker claim that such facts need not always enter the content of experience, and would not specifically enter the content of experience of the person (as in McGrath's example) who has "no idea what Bob Edwards looks like." While we say that we see Bob Edwards, we should not put too much weight on this way of talking. We see his facial features, his posture, and we see how he walks. Seeing all these things allows us to recognize the person to be Bob Edwards, should we know what Bob Edwards looks like. But him being Bob Edwards need not enter into the content of experience. More generally, recognitional concepts need not enter into the content of perception, although they enter into the beliefs formed on the basis of perception. ${ }^{3}$

McGrath also offers an extension case with a musical note:

Someone without perfect pitch may hear what is in fact a middle C. The property of being a $\mathrm{C}$ pitch enters the token content of the person's experience. Still, the person has no prima facie justification to believe a $\mathrm{C}$ pitch is present. The person doesn't know a $\mathrm{C}$ from a D from an A. There is no prima facie evidence that is somehow defeated or overridden (McGrath 2015).

In response, I do not see a reason to think that our conventional names for pitches enter the content of perception. What enters the content of perception is the particular note played with its timbre, resonance, tonality, and ring. The fact that humans have agreed to call the note a $\mathrm{C}$ need not have any repercussion for the content of experience. As in the case above, I am not denying that the fact that the note is a $\mathrm{C}$ could be part of what is heard, I am simply denying that it needs to be part of what is heard. The person McGrath describes, has prima facie justification that that pitch is present, where "that" singles out the pitch heard. She merely fails to recognize that pitch as a $\mathrm{C}$.

\section{Reply to Pautz}

Pautz begins his subtle and closely argued essay by challenging the thesis that a perceiver is more justified in believing certain things than someone who suffers a subjectively indistinguishable hallucination. He critically considers three possible lines of reasoning that I might use to support the thesis that a perceiver has more justification than a hallucinator. Thereby, he puts the ball back in my court to either defend one (or more) of these lines of reasoning, or offer another. He also invites me to consider problem cases involving seamless transitions between perceptions and hallucinations and graded perceptual justification. I will address these in turn.

\footnotetext{
${ }^{3}$ I am not saying that recognitional concepts never enter into the content of perception. For present purposes, I remain neutral on that matter. I am, however, arguing that they need not enter into the content of perception.
} 


\subsection{Why believe that Hallie is more justified than Percy?}

Consider again Percy and Hallie. Percy is perceiving a white cup, while Hallie is unbeknownst to her hallucinating a white cup. Both form the belief "that is a white cup". As I argue, Percy has more evidence than Hallie, since Percy has factive evidence and phenomenal evidence for his belief, while Hallie has only phenomenal evidence. I argue, moreover, that in virtue of having more evidence, Percy's belief is better justified than Hallie's belief: He is more justified in his belief "that is a white cup" since he has factive evidence in addition to phenomenal evidence. We can call the thesis that Percy has more evidence than Hallie Extra Evidence and the thesis that Percy's belief is better justified than Hallie's More Justification.

Pautz accepts for the sake of argument that Percy has more evidence than Hallie, but asks for more explanation as to why we should accept that Percy's belief is better justified than Hallie's in virtue of having more evidence. So he questions More Justification even assuming Extra Evidence. He offers three routes I might take to support the move from Extra Evidence to More Justification: (1) by invoking the stronger linkage principle, that is, the principle that the linkage to the environment is stronger when one perceives than when one hallucinates, (2) by invoking the principle that more evidence yields more justification, and (3) by invoking standard Bayesianism.

I will address Pautz's three options in turn, but before I do so it is important to note that these three options are not incompatible. Indeed, they complement one another. I argue for the stronger linkage principle and accept the standard principle that more evidence yields more justification. I will say a bit more about both shortly. While I do not, in the paper at hand, develop an account of how evidence and justification interact with confidence and do not elaborate on how the capacity view would cohere with standard Bayesian principles, the reason for this is simply that one cannot do everything in a short paper. As I will explain, there is-contra Pautz-nothing in my view that would be at odds with accepting standard Bayesian principles.

First, let me address Pautz's question about the stronger linkage principle. Pautz quotes the following passage from me in relation to this idea:

[Factive evidence] is evidence of a different kind insofar as the systematic linkage to the environment is stronger than the one governing phenomenal evidence. More specifically, it is evidence of a different kind because it is provided by successfully employing perceptual capacities in a particular environment. So factive evidence provides a rationality boost beyond the one that a perceiver already has from phenomenal evidence (Pautz 2015).

He asks what 'stronger' amounts to with respect to linkage. In response, the sense in which the linkage to the environment is stronger in the case of perception than in the case of hallucination is that the conditions that make experience evidentially forceful are optimal in the case of perception. After all, in perception we are perceptually related to our environment while in hallucination we fail to be so related. I understand perception as the product of employing perceptual capacities, such as capacities to discriminate and single out particulars in one's environment. I 
argue that a perceiver's mental states in perception and our mental states in total hallucination are linked to the environment via the perceptual capacities employed. This is what gives them their evidential force. When one hallucinates, one's mental state is linked to the environment insofar as the perceptual capacities employed are determined by relations to particulars. While these relations to particulars fail to actually hold in the case of hallucination, the perceptual capacities employed are nonetheless determined by the relations that would hold were one in the good case. When one perceives, one's mental state is linked to the environment not just because of the perceptual capacities employed, but since one is in fact perceptually related to one's environment. It lies in the very nature of perceptual capacities to successfully discriminate and single out particulars when conditions are right. In the good case, our perceptual capacities single out the very particulars they purport to single out: The linkage between the perceptual state is as strong as it can get. In nonideal cases, such as illusion or hallucination, we purport yet fail to single out particulars. As I argue in the paper, it is because perceptual discriminatory capacities are by their nature linked to the good case that they manage to provide evidence and become rational to heed. So what I am saying in the passage Pautz quotes is that factive evidence is specially tied into the very success conditions that make perception evidentially forceful in the first place.

Second, let me address Pautz's question about the principle that more evidence yields more justification (as discussed in Fantl and McGrath 2002, 2009). Since what is specifically at issue is whether adding factive evidence on top of phenomenal evidence should yield a justificatory boost, it will be most useful to speak to this specific case. The preceding discussion of strong linkage provides my explanation. The justificatory boost of factive evidence is due to (1) the idea that the justification of a belief is rooted in the degree to which it is supported by the evidence, (2) the idea that perceptual discriminatory capacities provide evidence because they are by nature linked to the good case, and (3) the idea that factive evidence has a special (maximally) strong linkage to the good case. In other words, adding factive evidence on top of phenomenal evidence strengthens the linkage to the success conditions which make perception justificatory in the first place.

Now Pautz thinks my version of Extra Evidence does not support More Justification given standard Bayesian principles. What leads Pautz to say this is that he reads what evidence one has off of how one would articulate that evidence. As he puts it:

In sum, Schellenberg's view of the two types of evidence, together with their ordinary-language characterizations, may be put as follows:

Common Phenomenal Evidence: that cup is white.

Percy's Extra Factive Evidence: that cup is white (Pautz 2015).

In response, while it is true that Hallie would articulate her evidence with "that cup is white", this does not mean her evidence is "that cup is white". The evidence one has and how one would articulate that evidence are two very different things. There is no reason to think that verbal expression of an experience is a good guide to the content of the experience and thus the evidence one has. Moreover, if the verbal expression of an experience would be an expression of one's evidence that would 
rule out any externalist account of evidence. Pautz's way of putting things in the passage above is problematic since equating the evidence one has with how one would articulate that evidence would not only over-intellectualize the content of experience, it would eradicate any differences in evidence that are not accessed by the experiencing subject. In short, "that cup is white" is not the evidence one has when one suffers a hallucination as of a white cup, it is merely the way one might articulate one's evidence. Further along in his paper, Pautz writes:

As for Hallie, Schellenberg's view is that Hallie's total evidence includes "phenomenal evidence" which, she says, can be articulated by saying "that cup is white". So it is very natural to suppose that, on Schellenberg's view, Hallie's phenomenal evidence also simply entails Cup, even if that evidence happens to be false (Pautz 2015).

Cup according to Pautz is the proposition "there really is a white cup present" (Pautz 2015). By conflating the evidence one has with how one would articulate that evidence, Pautz is lead to claim that on my view

both Hallie and Percy are in possession of evidence that entails Cup. In that case, given standard Bayesianism, Schellenberg's own version of Extra Evidence fails to support her assertion of More Justification, that is, her assertion that Percy's evidence supports the belief in Cup 'to a higher degree' than does Hallie's evidence (Pautz 2015).

He goes on to say that both Percy and Hallie's evidence has probability 1 conditional on their total evidence.

In response, Hallie does not have evidence that entails Cup, and so there is no Bayesian argument that Hallie has maximal evidence for Cup. Her evidence is determined by a content schema. Indeed, as I argued above, Hallie does not have the evidence "that cup is white", even though she may articulate her evidence in that way when expressing a belief based on her experience. More generally, although one would articulate the evidence in exactly the same way, the evidence in subjectively indistinguishable good and bad cases is different. Given that the experiences are subjectively indistinguishable, it better be the case that one would articulate them in exactly the same way. Percy does not appreciate his evidence as being factive. Hallie does not appreciate her evidence as being merely phenomenal. Of course, Hallie may falsely believe that there really is a cup there due to it seeming to her that there is a cup there. Hallie may falsely believe all sorts of things. Hallie falsely believing that there really is a cup there does not imply that she has evidence that there really is a cup there.

On the capacity view, Percy is in possession of factive evidence that entails Cup and so-at least assuming standard Bayesian principles-Cup has probability 1 on his evidence. But Hallie does not have the factive evidence that Hallie possess, and so Cup does not have probability 1 on her evidence. This is all we need to support More Justification. So contra Pautz, Hallie and Percy have different evidence. Only Percy has evidence that entails Cup, and so only Percy's evidence is such that Cup has probability 1 on it. So Percy's evidence (call it $E_{p}$ ) entails Cup, whereas Hallie's evidence $\left(E_{h}\right)$ does not entail Cup. So, we can have both of the following: 
1. $\operatorname{Pr}\left(\operatorname{Cup} \mid \mathrm{E}_{\mathrm{p}}\right)=1$.

2. $\operatorname{Pr}\left(\operatorname{Cup} \mid \mathrm{E}_{\mathrm{h}}\right)<1$.

Now Bayesians model learning via conditionalization, and post-conditionalization, propositions learned must receive probability 1. Standard Bayesianism does not commit one to the idea that the evidence one has is represented by the propositions one conditionalizes. It is important to separate the question of how to properly model "learning" from how to individuate a subject's evidence. Bayesians need not identify the evidence a subject has with the propositions to which they assign maximal credence (or to those on which they have conditionalized or "learned"). Indeed, Bayesians are free to count uncertain claims as part of an agent's evidence. ${ }^{4}$ So Bayesians are free to say that the experiencing subject is less than certain in the proposition $p$ which encodes the content of her hallucination-so long as she has not conditionalized on it, that is, so long as she has not updated on $p$ via conditionalization). So my version of Extra Evidence supports More Justification and, moreover, nothing in my view precludes me from appealing to standard Bayesianism to support More Justification. Once one departs from standard Bayesianism and allows alternatives to strict conditionalization to model the learning process (e.g., Jeffrey conditionalization), then it is no longer required that all "learned" propositions have probability 1 . This is an attractive alternative that I am sympathetic to. However, as I hope to have shown above, the capacity view is compatible even with Standard Bayesianism. ${ }^{5}$

\subsection{Seamless Transitions}

Pautz goes on to raise two problem cases for my view, the first of which is seamless transition:

Seamless Transition Case. Hallie starts out having a perfect hallucination of a white cup on a table, although she has no idea that she is hallucinating. Then her hallucination ceases, but at the same time a white cup is placed on a table before her. The result is that she transitions between hallucination and veridical perception. Yet there is no phenomenal change in her experience. In fact, there is also no other change in her phenomenal life at all. Even so, suppose that, at the transition point, Hallie becomes more confident in Cup, the proposition that there is a white cup there (Pautz 2015).

Pautz (rightly) says that my view is that at the transition point, Hallie's belief in the proposition that there is a white cup there (Cup) becomes justified to a higher degree than before. That is after all a consequence of More Justification. But Pautz then says, "we find this verdict to be radically mistaken." He adds that Hallie's increase in confidence seems "totally capricious and irrational."

As I see it, Pautz has conflated two points. I agree with him that Hallie's increase in confidence seems totally capricious and irrational. But that is because her

\footnotetext{
4 See, Joyce (2005) for a helpful discussion on these issues.

5 Thanks to Branden Fitelson for a helpful email exchange on these issues.
} 
increase in confidence is not motivated on the basis of engagement with reasons. The case itself is underdescribed insofar as we are not told why Hallie shifts her confidence at that crucial moment; it sounds as if she has randomly shuffled her credences. That would indeed be a capricious and irrational doxastic basis on which to form any credence whatsoever, irrespective of what the propositional evidence in fact supports.

Pautz's intuition is that Hallie has the same evidence from beginning to end even though she is first hallucinating and at the end perceiving. By my lights, the main reason to reject Pautz's intuition that Hallie has the same evidence from beginning to end is that in the perceptual phase, Hallie has factive evidence in addition to phenomenal evidence. Hallie's perceptual discriminatory capacities are now placed in the very case that by nature they get right. But never mind my specific reasons for disagreeing with Pautz on this point. Anyone who supports either Extra Evidence or More Justification, and moreover anyone who has the externalist intuition that the perceiver is evidentially in a better epistemic situation than the hallucinator, should disagree with Pautz here. Pautz's intuition is a distinctively internalist intuition which many will be motivated to reject. Once one sees that we can accept Pautz's point that Hallie's increase in confidence is totally capricious and irrational, while still accepting my view (or some other externalist view), then Pautz owes us some further reason to accept the internalist stance he proposes.

\subsection{Graded Justification}

The second problem case that Pautz raises for my view is that of graded justification:

The Complex Percy Case. Percy is having an ordinary veridical experience of two uniformly colored tomatoes and two uniformly colored bananas on a table in ideal light. It is obvious to him that each of the tomatoes is a shade of red and that each of the bananas is a shade of yellow. So he has a great deal of justification for believing these simple color propositions. What is less obvious to him is whether the shades of red of the two tomatoes are different. It kind of seems to him that they are, and if forced to choose he would go for the "different" option, but he cannot be so confident. (If it is a case of a difference in color, it is what practitioners of psychophysics call a just noticeable difference in color.) Likewise, it kind of seems to him that the distance between the tomatoes is slightly greater than the distance between the bananas. While he isn't justified in outright believing this, his experience justifies him in having some level of "credence" in it (Pautz 2015).

Pautz asks, what it is about the experience or circumstances that explains the different degrees of justification for these different propositions? As Pautz notes, I want to argue that justification is graded. I agree with Pautz that it is a virtue of the capacity view that it provides a way of accounting for graded justification and that many proposals currently on the table do not have room to account for graded justification. I do not, however, want to accept any of the proposals that Pautz suggests on my behalf. But this is not Pautz's fault: I say very little in the paper as to 
what accounts for the gradedness of justification. For the sake of simplicity, I discuss only perfectly good cases of perceptions, illusions, and radical hallucinations, that is, hallucinations which are subjectively indistinguishable from perceptions but in which one does not in fact see what one seems to be seeing. Naturally, there are many intermediate and hybrid cases. One can get one property-instance wrong or many. One can get one object wrong or many. One can confuse one aspect of an event or many. The more one gets wrong, the worse one's epistemic situation.

The way I account for this is in terms of more or less gappy propositions. So I want to argue that justification is graded in virtue of the gappiness of propositions. This can be interpreted as a matter of strength of linkage. The more gappy the proposition the weaker the immediate linkage with the environment of the experiencing subject.

\section{Reply to Neta}

My thanks to Ram Neta for so clearly situating my project as aiming to reconcile internalist and externalist intuitions, and for raising a number of challenging questions.

\subsection{Perceptual content}

Neta asks why we should think that perception is representational, something I assume in the paper at hand. In response, this is a great question, and-as Neta notes-Travis (2004) has raised important challenges to representationalist views (see also Martin 2004). I have given a full length reply to these challenges elsewhere (Schellenberg 2011, see also Schellenberg 2014b), but will content myself here with a brief synopsis of my argument for perception being representational:

P1: $\quad$ If a subject is perceptually related to her environment (while not suffering from blindsight or any other form of unconscious perception), then she is sensorily aware of her environment

P2: If a subject is sensorily aware of her environment, then her environment sensorily seems a certain way to her

P3: If her environment sensorily seems a certain way to her, then she has an experience with content $C$, where $C$ corresponds to the way her environment sensorily seems to her

Conclusion 1: If a subject is perceptually related to her environment (while not suffering from blindsight or any other form of unconscious perception), then she has an experience with content $C$, where $C$ corresponds to the way her environment sensorily seems to her

P4: Her environment is either the way it sensorily seems to her or it is different from the way it sensorily seems to her

P5: If a subject has an experience with content $C$, then $C$ is either accurate (if her environment is the way it sensorily seems to her) 
or inaccurate (if her environment is not the way it sensorily seems to her)

Conclusion 2: If a subject is perceptually related to her environment (while not suffering from blindsight or any other form of unconscious perception), then the content of her experience is either accurate or inaccurate (Schellenberg 2014b: 207)

The core idea is that perceptual capacities can be employed such that they single out particulars or fail to single out particulars. Employing such perceptual capacities explains the sensory character of experience. The the accuracy conditions on the employment of perceptual capacities suffice to imbue them with a minimal sort of representational content, since they are thereby the sorts of things that can be accurate about the world or not.

\subsection{Perceptual capacities and evidence}

Neta's second question is what the connection is between viewing perceptual capacities as functioning to single out particulars in the environment, and viewing them as providing evidence for what they are of in the good case. In response, it is because perceptual capacities function to single out particulars in the environment that they provide evidence for what they are of in the good case. Why think this? My argument is that sensory states provide phenomenal evidence since the perceptual capacities employed in perceptual experience are systematically linked to their employment in the good case insofar as perceptual capacities are determined by relations between perceivers and their environment. After all, the function of the capacity is to differentiate and single out, say, instances of red in perception. In this sense, there is a metaphysical priority of the good over the bad case in characterizing the nature of perceptual capacities. In virtue of this metaphysical priority of the good over the bad case phenomenal states provide us with evidence.

Now, Neta raises the issue that "the primal sketch" in Marr's theory of vision also seems to function to single out particulars in the environment, but does not itself yield any evidence for the subject. What is the relevant difference (if any)? In response, the primal sketch in Marr's theory of vision is subpersonal and accordingly does not itself yield evidence for the subject. But perceptual discriminatory capacities, producing subject-level perceptual content, are capable themselves of providing evidence for the subject—or so I argue. To be sure, I have not given an argument in support of the thesis that the primal sketch does not provide evidence of some sort. It may well be understood as providing evidence to the perceptual system at a subpersonal level. If that were the case that would not be a problem for my view. The crucial point is that to provide evidence at a subpersonal level is not to provide evidence for the experiencing subject.

\subsection{Gappy content and evidence}

A further question that Neta raises is if and how I can reconcile the ideas that (1) the content of hallucination is gappy, (2) hallucinators have evidence, and (3) evidence is constituted (among other things) by a proposition? In response, I accept all three 
claims and will explain how they are consistent. I understand perceptual experience as characterized by two levels of content: a content token and content type. In the case of a hallucination, the content token is gappy. The content type is a content schema, that is, it is a potentially particularized content. This content schema is a derived notion of content that subjectively indistinguishable perceptions, hallucinations, and illusions have in common. Hallucinators have phenomenal evidence in virtue of their mental state being characterized by these two levels of content. No doubt a gappy proposition is a strange proposition, but it is a proposition nonetheless. As I argue elsewhere, a gappy proposition is best thought of as necessarily false (Schellenberg 2010, 2013b). After all, if a content is gappy then it infallibly fails to be accurate of the world. If the gappy content is necessarily false, then it has a truth value. The derived notion of content- the content type-can by contrast either be accurate or inaccurate of the world.

What does this entail for the justificatory role of hallucinations? Consider the gappy content $<\operatorname{MOPo}\left({ }_{-}\right) \operatorname{MOPF}\left({ }_{-}\right)>$, where $\operatorname{MOPo}\left({ }_{-}\right)$in the object-place is a gappy, object-related de re mode of presentation and $\mathrm{MOPF}\left({ }_{-}\right)$in the property place is gappy, property-related de re mode of presentation that would single out an instance of the property $\mathrm{F}$, where one perceptually related to such an instance. It seems to the hallucinator whose mental state is characterized by such a content that "There is an $\mathrm{x}$ Fx". An important point in this context is that the gappy content $<\operatorname{MOPo}(\ldots)$, $\operatorname{MOPF}\left(\_\right)>$justifies "There is an $\mathrm{x} \mathrm{Fx"} \mathrm{but} \mathrm{it} \mathrm{does} \mathrm{not} \mathrm{entail} \mathrm{"There} \mathrm{is} \mathrm{an} \mathrm{x} \mathrm{Fx".}$ What logically follows from the gappy content $<\operatorname{MOPo}\left(\_\right), \operatorname{MOPF}\left({ }_{-}\right)>$and what the subject is justified in believing on the basis of $<\operatorname{MOPo}\left(\_\right), \operatorname{MOPF}\left(\_\right)>$come apart. We are justified in believing what logically follows, but we are also justified in some other things, for example things that seem to logically follow. Since I argue that the content of hallucination is gappy and therefore necessarily false, and since I argue moreover that the content of hallucination provides phenomenal evidence, I am arguing that not all evidence is known (and indeed that not all evidence is true). In this way my view diverges, for instance, from that of Williamson, who equates the subject's evidence with what she knows. But in this way, I am able to reconcile the three points with which Neta is concerned.

\subsection{The epistemic difference between Percy and Hallie}

Neta raises a series of questions that center on how we should think about the epistemic difference between Percy and Hallie. I have addressed some of these questions in my responses to McGrath and Pautz above and so will focus on those elements that go beyond the questions that McGrath and Pautz raise. Neta asks what the status is of the claim that Hallie and Percy have evidence in common. In particular, he asks whether this claim is treated as a datum or as a feature of my view that recommends it in some way. In response, this strikes me as a false dilemma. Datum is a strong notion. The notion that Hallie and Percy have evidence in common is a plausible first pass assumption that could possibly be overridden. So in that sense, it is not a datum, but rather something that should be explained. I hope to have given an explanation for why Hallie and Percy have evidence in common (see in particular Schellenberg 2013a). 


\subsection{Evidence and the rationality of Credal States}

Neta asks how evidence bears on the rationality of mental states other than beliefs, such as credences. He imagines a case in which one is first perceiving a white cup $\left(\operatorname{cup}_{1}\right)$ and then starts hallucinating a cup. Neta asks "what implications does this new hallucination have for the rationality of Percy's states of comparative confidence, or for her rationality of her degrees of confidence?" In response, I would say that the subject in this case has phenomenal and factive evidence for the presence of $\operatorname{cup}_{1}$ and phenomenal evidence for the cup he is hallucinating. In contrast to Neta, I see no reason for thinking that his evidence for the presence of cup $_{1}$ changes after he has started to hallucinate an additional cup-while still perceiving cup $_{1}$. After all, he does not know he is hallucinating an additional cup. So he has no reason to doubt his over all epistemic standing. Moreover, there are good reasons to treat separately the fact that he is veridically perceiving cup $_{1}$ while hallucinating an additional cup. We do not have to treat these two aspects of his current mental state as interfering with one another.

Following on my response to Pautz above, I would say that his rational confidence in $\operatorname{cup}_{1}$ being present is 1 (before and after he starts hallucinating the second cup), but that his rational confidence in an additional cup being present is lower. After all, he is hallucinating rather than perceiving that additional cup. Parallel to what I said about evidence above, I see no reason to think that hallucinating an additional cup should lower his rational confidence in the presence of cup ${ }_{1}$. This approach goes hand in hand with arguing that the rationality of his degree of confidence will change as his environment changes. In that sense, I am following the standard externalist approach about rationality in holding that the amount of rational confidence one has can change due to external factors. ${ }^{6}$

Neta ends his comments by asking how my view compares to other alternative views in the literature, such as the views of Sosa as well as Plantiga, Williamson, and Burge. In response, I have, in this paper, not tried to refute alternative views, but have focused rather on developing my positive proposal. To compare my view to these other views would require at minimum four separate papers. I have elsewhere discussed the difference between my view and Sosa's, Burge's, and Williamson's (see Schellenberg 2013a, 2014a). ${ }^{7}$ But, if only to take up an invitation to say something that might be of interest, I think I can say something fairly brief by way of at least comparing my approach with that of Sosa. Sosa develops his notion of competences (or capacities) in reliabilist terms. In doing so, his view is subject to all the well-known problems that reliabilism faces. ${ }^{8}$ Insofar as the capacity view that I have put forward is distinctly non-normative and non-reliabilist it avoids these

\footnotetext{
${ }^{6}$ For an argument that we have no good grip on what counts as evidence for $\mathrm{p}$ that does not enter into determining one's rational level of confidence that $\mathrm{p}$, see Neta (2008).

7 See also the comparison of Williamson and my views in Pautz's contribution to this volume.

8 For example, Lehrer's (1990) Truetemp counterexample: Mr. Truetemp has, unbeknownst to him, a temperature-detecting device implanted in his head that regularly produces accurate beliefs about the ambient temperature.
} 
problems. My capacity view is compatible with a broadly virtue-based epistemology, and by adopting it Sosa could resolve this trouble.

As I argue, it is in virtue of the primacy of the good over the bad case that the mental states yielded by employing capacities have epistemic force. So there is no sense in which the epistemic force of mental states yielded by employing capacities is understood in terms of the reliability of the capacities employed. Of course, it might be that the capacities are reliable, but even if that is so, that is not what imbues the mental state with its epistemic force. So neither the capacities nor the metaphysical and explanatory primacy notions in play need be understood in terms reliability or any normative ways. Indeed, the capacity view shows how the epistemic force of experience is grounded in metaphysical facts about experience. Moreover, while Sosa does not appeal to phenomenal and factive evidence, nothing in his view should preclude him for accepting the two levels of evidence that I propose.

\section{References}

Bergmann, M. (2006). Justification without awareness. Oxford: Oxford University Press.

Burge, T. (2003). Perceptual entitlement. Philosophy and Phenomenological Research, 67, 503-548.

Crane, T. (2011). The singularity of singular thought. Aristotelian Society Supplementary, 85, 21-43.

Fantl, J., \& McGrath, M. (2002). Evidence, pragmatics, and justifcation. Philosophical Review, 111, 67-94.

Fantl, J., \& McGrath, M. (2009). Knowledge in an uncertain world. Oxford: Oxford University Press. Graham, P. (2011). Epistemic entitlement. Nous, 46, 449-482.

Greco, J. (2001). Virtues and rules in epistemology. In A. Fairweather \& L. Zagzebski (Eds.), Virtue epistemology. Oxford: Oxford University Press.

Jeshion, R. (2010). Singular thought: Acquaintance, semantic instrumentalism and cognitivism. In R. Jeshion (Ed.), New essays on singular thought (pp. 105-140). Oxford: Oxford University Press.

Joyce, J. (2005). How probabilities reflect evidence. Philosophical Perspectives, 19, 153-178.

Lehrer, Keith. (1990). Theory of knowledge. Boulder, CO: Westview.

Martin, M. (2004). The limits of self-awareness. Philosophical Studies, 103, 37-89.

McGrath, M. (2015). Schellenberg on the epistemic force of experience. Philosophical Studies. doi:10. 1007/s11098-015-0529-7.

Neta, R. (2008). What evidence do you have? British Journal for the Philosophy of Science, 59, 89-119.

Pautz, A. (2015). What is my evidence that here is a cup. Philosophical Studies. doi:10.1007/s11098-0150531-0.

Sainsbury, M. (2010). Intentionality without exotica. In R. Jeshion (Ed.), New essays on singular thought (pp. 105-140). Oxford: Oxford University Press.

Schellenberg, S. (2010). The particularity and phenomenology of perceptual experience. Philosophical Studies, 149, 19-48.

Schellenberg, S. (2011). Perceptual content defended. Noûs, 45(4), 714-750.

Schellenberg, S. (2013a). Experience and evidence. Mind, 122, 699-747.

Schellenberg, S. (2013b). Externalism and the gappy content of hallucination. In F. E. Macpherson \& D. Platchias (Eds.), Hallucination (pp. 291-311). Cambridge: MIT Press.

Schellenberg, S. (2014a). The epistemic force of perceptual experience. With a response by Alex Byrne, Philosophical Studies.

Schellenberg, S. (2014b). The relational and representational character of perceptual experience. In B. Brogaard (Ed.), Does perception have content?. New York: Oxford University Press.

Sosa, E. (1991). Knowledge in perspective. Cambridge: Cambridge University Press.

Travis, C. (2004). Silence of the Senses. Mind, 113, 57-94. 